\title{
Effect of cognitive rehabilitation program based on memory on the working memory profile and prospective memory in hearing loss students
}

\author{
Mohammad Ashori', Ashkan Tajvar Rostami \\ 1-Assistant Professor, Department of Psychology and Education of Children with Special Needs, Faculty of \\ Education and Psychology, University of Isfahan, Isfahan, Iran (Corresponding Author). \\ E-mail: m.ashori@edu.ui.ac.ir \\ 2- M.A. Student in Clinical Psychology, Islamic Azad University, Najafabad Branch, Najafabad, Iran.
}

Received: 23/08/2019

Accepted: 21/01/2020

\begin{abstract}
Introduction: Hearing loss affects different aspects of life, while the use of a cognitive rehabilitation program based on memory is associated with desirable outcomes.

Aim: The aim of present study was to investigation the effectiveness of cognitive rehabilitation program based on memory on the working memory profile and prospective memory in hearing loss students.
\end{abstract}

Method: The present research was a quasi-experimental study with pre-test, post-test design and control group. The participants were 24 male hearing loss students from schools in Shahr-e-Kord city who selected through convenient sampling method. Subjects were divided into experimental and control groups, each group consisted of 12 students. The experimental group received 10 sessions of cognitive rehabilitation program based on memory, while the control group did not. The instruments of research were working memory test battery for children and prospective and retrospective memory questionnaire. Data were analyzed by MANCOVA.

Results: The results showed that cognitive rehabilitation program based on memory had a significant effect on the working memory and prospective memory in the experimental groups $(\mathrm{P}<0.0001)$.

Conclusion: According to the findings, cognitive rehabilitation program based on memory improved working memory profile and prospective memory in hearing loss students. So, this program can be used to improve of working memory profile and prospective memory of these students and planning for providing of cognitive rehabilitation program based on memory for them have special importance.

Keywords: Cognition, Working memory, Prospective memory, Hearing loss

How to cite this article : Ashori M, Tajvar-Rostami A. Effect of cognitive rehabilitation program based on memory on the working memory profile and prospective memory in hearing loss students. Shenakht Journal of Psychology and Psychiatry. 2020; 6 (6): 40-54 .URL: http://shenakht.muk.ac.ir/article-1-621-fa.pdf

Copyright $\odot 2018$ the Author (s). Published by Kurdistan University of Medical Sciences. This is an open access article distributed under the terms of the Creative Commons Attribution-Non Commercial License 4.0 (CCBY-NC), where it is permissible to download, share, remix, transform, and buildup the work provided it is properly cited. The work cannot be used commercially without permission from the journal. 


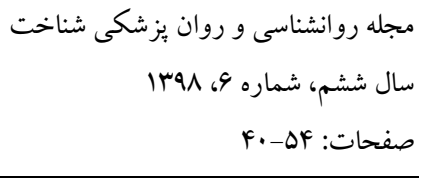

\title{
اثربخشى برنامه توانبخى شناختى مبتنى بر حافظه بر نيمرخ حافظه فعال

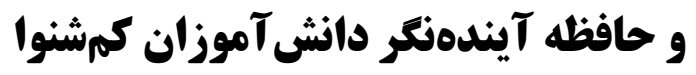

\author{
محمد عاشورى '، اشكان تاجور رستمى ' \\ ا.استاديار، گروه روانشناسى و آموزش كود كان با نيازهاى خاص، دانشكده علوم تربيتى و روانشناسى، دانشگاه اصفهان، اصفهان، ايران (مولف مسئول). \\ ايميل:m.ashori@edu.ui.ac.ir \\ ז. دانشجوى كارشناسى ارشد روانشناسى بالينى، دانشكاه آزاد اسلامى، واحد نجف آباد، نجف آباد، ايران. \\ تاريخ بذيرش مقاله: |+|||

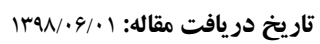

جكيله

مقدمه: كمشنوايى بر ابعاد مختلف زندگى تأثير مى گذارد درحالى كه استفاده از برنامه توانبخشى شناختى مبتنى بر حافظه با نتايج مطلوبى همراه است.

هدف: اين ئزوهش با هدف بررسى اثربخشى برنامه توانبخشى شناختى مبتنى بر حافظه بر نيمرخ حافظه فعال و حافظه آيندهنگ دانش آموزان كمشنوا انجام شد.

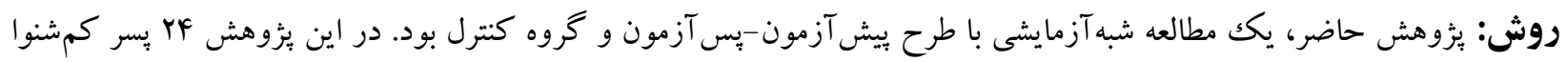

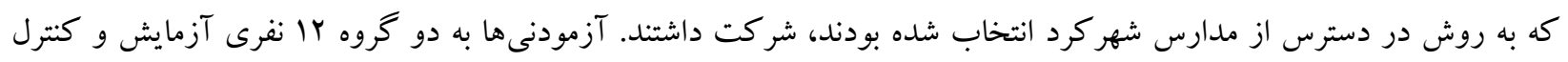

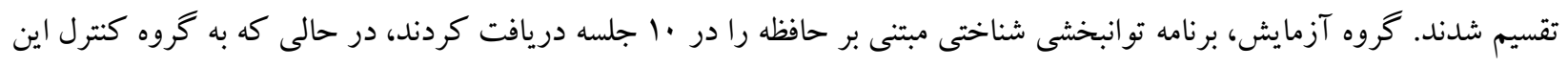

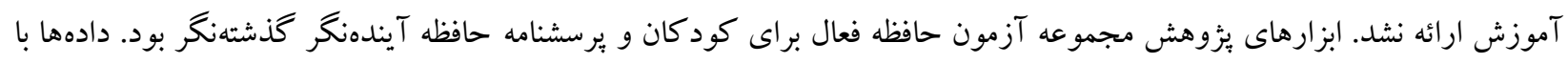

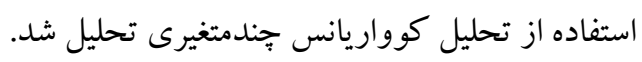

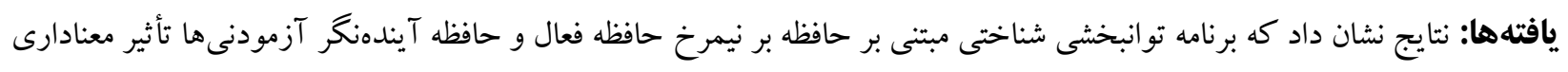
داشت (P<. (P) نتيجه كيرى: از برنامه توانبخشى شناختى مبتنى بر حافظه مىتوان براى بهبود حافظه فعال و حافظه آيندهنخر دانش آموزان كمشنوا بهره

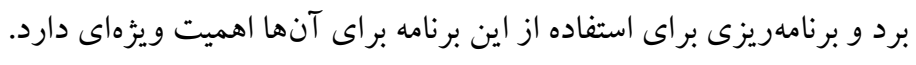
كليدوازهها: شناخت، حافظه فعال، حافظه آيندهنگر، كمشنوا 


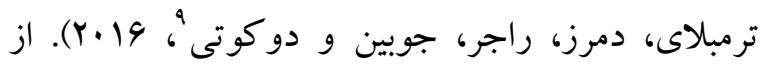
طرفى، كود كان كمشنوا در به خاطر سبردن و يادآورى جرى اطلاعات يا انجام عملى كه بايد انجام دهند مشكل دارند. اين كود كان در كاركردهاى مختلفى كه حافظه دارد با با.

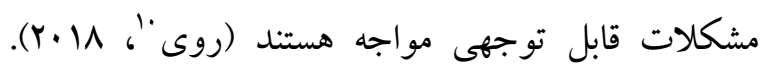
حافظه فعال، نظام جامعى است كه خردهنظامها و و عملكردهاى حافظه كوتاهدت و بلندمدت را به هم متصل مى سازد و به جهار بخش مجرى مركزى" "، حملقه

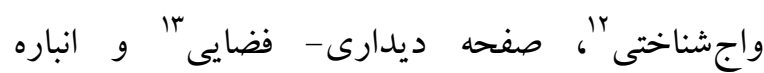
رويدادى ^" تقسيم مى شود (ارجمندنيا، شريفى و رستمى،

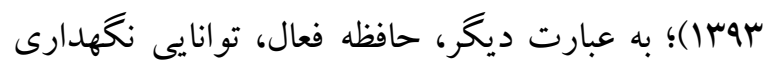
اطلاعات در ذهن در حين انجام تكاليف بييجيده است و شامل توانايى نظارت بر عملكرد و ارزيابى بردازشهاى شناختى مىشود و به عنوان سامانهاى ذهنى وظيفه

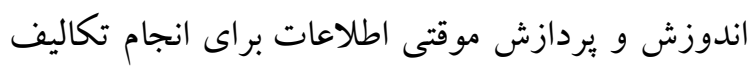

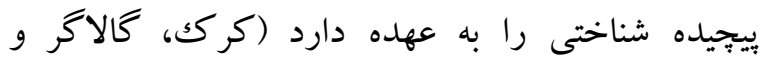

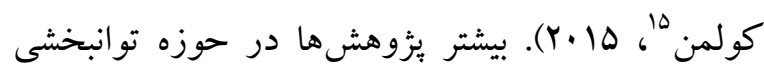
شناختى درباره حافظه به صورت كلى يا درباره حافظه

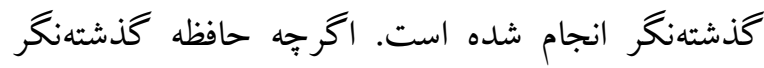
نوعى توانايى شناختى مهم درباره امور كذشته است اما براى انجام بسيارى از فعاليتها به نوعى توانايى ديخر، به نام حافظه آيندهنگر نياز داريم (ميونى، استابلوم،

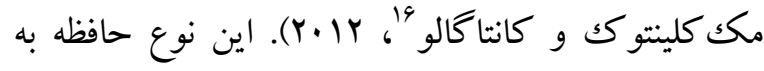
توانايى تنظيم اهداف و اعمال آينده و سبس نخهدارى و

\footnotetext{
${ }^{9}$. Dagenais, Rouleau, Tremblay, Demers, Roger, Jobin \& Duquette ${ }^{10}$. Roy

${ }^{11}$. Central executive

12. Phonological lop

${ }^{13}$. Visual spatial sketchpad

${ }^{14}$. Episodic buffer

15. Kirk, Gallagher \& Coleman

${ }^{16}$. Mioni, Stablum, McClintock \& Cantagallo
}

\section{مقلمهه}

در حال حاضر آموزش دانش آموزان ناشنوا و سختشنوا' منعكس كننده اين واقعيت است كه ديدكاه متخصصان نسبت به آنها تغيير كرده است و تلاش زيادى براى بهبودبخشى به كيفيت آموزش آنها مىشود (لاوير'ا

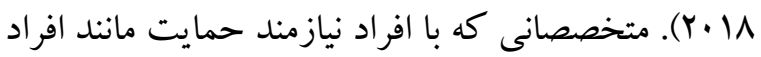
ناشنوا و كمشنوا كار مى كنند بايد در هنگام ارزيابى و درمان از تفاوتهاى فرهنگى و زبانى آكاه باشند و براى اصلاح رويكرد خود تلاش كنند. در حقيقت، افراد ناشنوا و كمشنوا نسبت به افراد عادى در زمينه سلامت و بهداشت روان به مراقبت بيشترى نياز دارند و بر آورده نشدن اين نياز يكك جالش بزرگك براى آنها محسوب

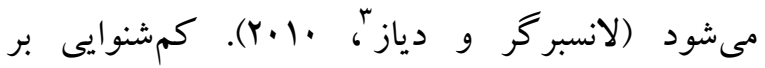
فعاليتهاى شناختى و هيجانى افراد تأثير مى گذارد و كودكان كمشنوا نسبت به كودكان عادى، مشكلات بيشترى را تجربه مى كنند (عاشورى، لوهו) و اين جالشها تأثيرى منفى بر عملكرد آنها در حوزههاى

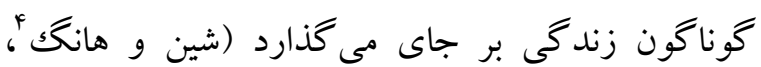
(Y.IV حوزههاى مهمى هستند كه كمشنوايى بر آنها تأثير

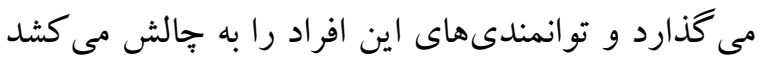

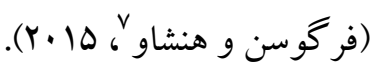

امروزه حافظه فعال به عنوان يكك موضوع مهم مورد توجه واقع شده و توجه بسيارى از متخصصان را به خود جلب

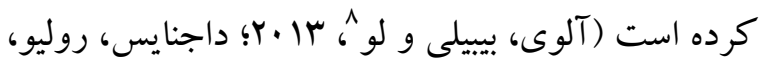

\footnotetext{
${ }^{1}$. Deaf and hard of hearing students

${ }^{2}$. Lawyer

3 . Landsberger \& Diaz

4. Shin \& Hwang

${ }^{5}$. Working memory

${ }^{6}$. Prospective memory

7 . Ferguson \& Henshaw

${ }^{8}$. Alloway, Bibile \& Lau
} 
توانبخشى بر اصل شكل يذيرى و خودترميمى مغز از

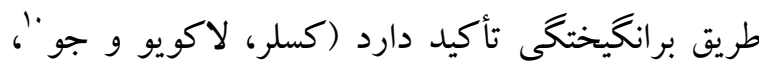
11 آץ؛ كانلويولوس، اندرسون، زلر، تامنز، فجل، والهود و همكاران"، 19.19). توانبخشى شناختى مبتنى بر حافظه به فرايندهاى شناختى و فعاليتهاى درمانى براى آموزش مهارتهاى مبتنى بر حافظه و ساير عملكردهاى شناختى به منظور يادآورى رويدادهايى گفته مىشود كه در زمانهاى مختلف اتفاق مىافتد يا افتاده است و در راستاى آن عملى انجام شده يا خواهد شد (بويت و رامل رَّا،

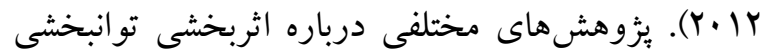
شناختى انجام شده است. در اين راستا، يافتهاى بثزوهش يرز مارتين و همكاران (Y.IV) نشان داد كه توانبخشى شناختى بر بهبود عملكرد حافظه فعال بيماران مبتلا به

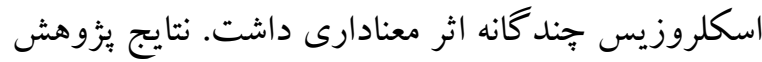

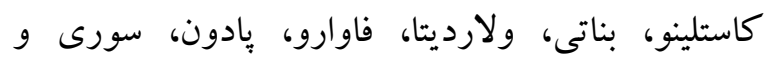

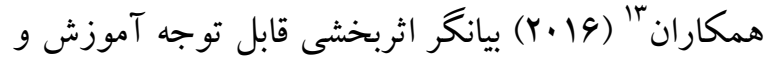
توانبخشى شنيدارى بر عملكرد شناختى، توجه و حافظه

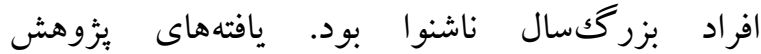
كانلويولوس و همكاران (19.19) حاكى از آن بود كه برد توانبخشى شناختى بر كاركردهاى اجرايى توجه و حافظه

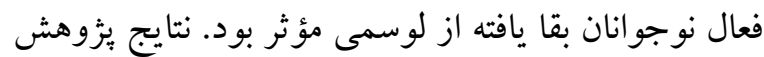

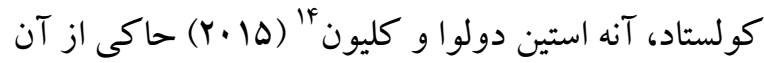
بود كه مشاركت مثبت در فعاليتهاى اوقات فراغت موجب بهبود مهارتهاى عصب روانشناختى از جمله حافظه، توجه و كاركردهاى اجرايى افراد كمشنوا مىشود. يافتهاى ئزوهش كسلر و همكاران (11)

${ }^{10}$. Kesler, Lacayo \& Jo

${ }^{11}$. Kanellopoulos, Andersson, Zeller, Tamnes, K., Fjell, Walhovd \& et. Al.

12. Boywitt \& Rummel

${ }^{13}$. Castiglione, Benatti, Velardita, Favaro, Padoan, Severi \& et. al.

${ }^{14}$. Kollstad, Anne-Stine Dolva \& Kleiven
ياد آورى مجدد آنها در زمان و بستر مناسب اشاره دارد

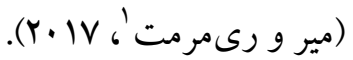
حافظه آيندهنگ به توانايى به ياد آوردن فعاليتهايى كه در آينده بايد انجام شوند مربوط است (يرز مارتين، گونزالس بِاتس، اگكادل ريو، كرويسر الياس و جيمنز

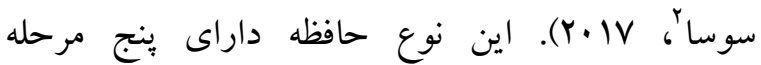

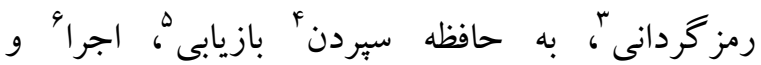

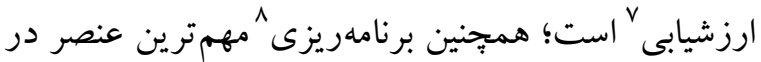
در اين مسير است (مير و رىمرمت، IV) كمشنوا در انجام عملى در زمان يكك رويداد خاص يا انجام فعاليتى پِ از تمام شدن فعاليت ديخر مشكل زيادى ندارند ولى در به ياد آوردن فعاليتى در زمانى

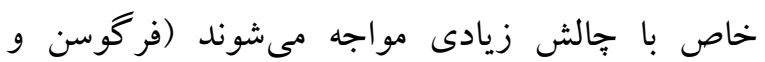
هنشاو، (Y) (Y). بهطور كلى، كود كان كمشنوا در حافظه به ويزه در حافظه فعال و حافظه آيندهنگ با مشكلات عمداى مواجه هستند. آنها فعاليتهايى كه بايد در آينده انجام دهند را فراموش مى كنند و نمىتوانند فعاليتها را طورى به خاطر بسِارند تا در زمان مناسب به ياد آورند

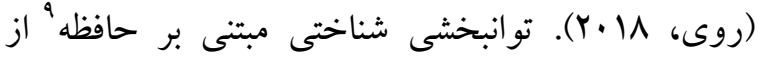
جمله روشهاى مؤثر در تقويت حافظه فعال و حافظه آيندهنگ است (داجنايس و همكاران، 19 ب.ب؛ يرز مارتين

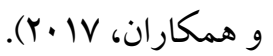

توانبخشى شناختى مبتنى بر حافظه رويكردى نظامدار است كه كاركردهاى مغزى و تنظيم هيجان را در هر فردى بهبود مىبخشد (عاشورى، 1هبا). اين نوع

\footnotetext{
1. Meier \& Rey-Mermet

2. Pérez-Martín, González-Platas, Eguíadel Rio, Croissier-Elías \& Jiménez Sosa

. Decoding

${ }^{4}$. Retain

5. Retrieval

${ }^{6}$. Executive

7. Evaluation

${ }^{8}$. Planning

${ }^{9}$. Cognitive rehabilitation program based on memory
} 
از آن جايى كه كمشنو ايى نقش بسيار مهمى در ياد كيرى دارد، استفاده از روشهاى مناسب آموزشى و توانبخشى آهى جهت بهبود مشكلات مربوط به حافظه فعال و تقويت حافظه آيندهنگ اهميت ويزٔهاى دارد (لورنس، جياكودى،

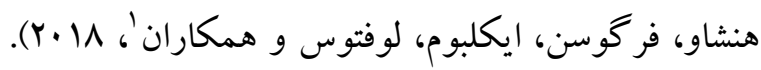
كودكان كمشنوا، توانايى توجه دقيق به جزئيات را ندارند و نمىتوانند از ظرفيت حافظه خود به خوبى

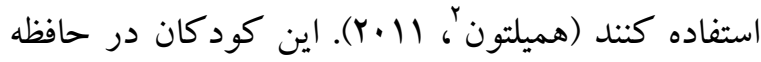
فعال و تقويت حافظه آيندهنگر با مشكل مواجه هستند

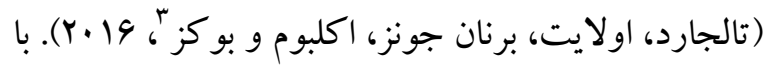
با توجه به بيشينه هاى ئزوهشى به نظر مىرسد استفاده از برنامه آموزشى توانبخشى شناختى براى بهبود حافظه فعال

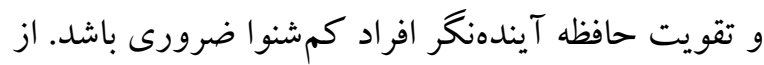
آن جايى كه حافظه هم بخشى از توانايىهاى شناختى است به نظر مىرسد با اجراى برنامه توانبخشى شناختى مبتنى بر حافظه، تغييرات مطلوبى در حافظه فعال و حافظه آيندهنگ اين افراد ايجاد شود. با توجه به اين كه

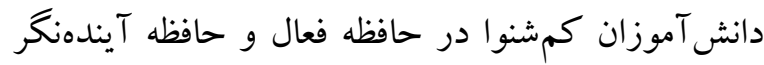
با مشكلات خاصى مواجه هستند و بزوهش هاى اندكى در اين حوزه انجام شده است كه حاكى خلاء يزوهشى و ضرورت بيش از بيش اين مطالعه است. يس هدف اصلى

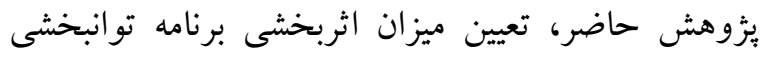
شناختى مبتنى بر حافظه بر نيمرخ حافظه فعال و حافظه آيندهنگ دانش آموزان كمشنوا است.

\section{روش}

${ }^{1}$. Lawrence, Jayakody, Henshaw, Ferguson, Eikelboom, Loftus \& et. Al.

${ }^{2}$. Hamilton

${ }^{3}$. Taljaard, Olaithe, Brennan-Jones, Eikelboom \& Bucks
حاكى از اثربخشى برنامه بازتوانى شناختى آنلاين بر

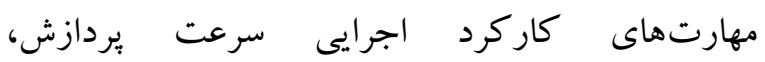
انعطاف يذيرى شناختى و حافظه اخبارى كلامى و بينايى كود كان با آسيب مغزى بود.

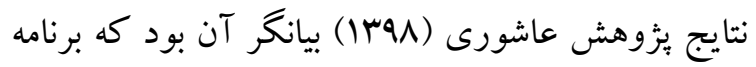
توانبخشى شناختى مبتنى بر حافظه، كار كردهاى اجرايى و تنظيم شناختى هيجان دانش آموزان با آسيب شنوايى را بهبود بخشيد. يافتهاى تحقيق زارع و شريفى (94) نشان داد كه توانبخشى شناختى رايانهاى بر بهبود عملكرد حافظه فعال و آيندهنگ بيماران مبتلا به اسكلروزيس

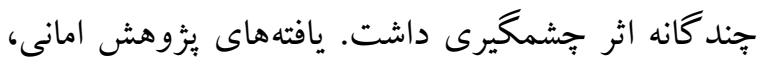
مظاهرى، نجاتى و شمسيان (1)99) حاكى از آن بود كه تو انبخشى شناختى بر كاركردهاى اجرايى توجه و حافظه فعال نوجوانان بقا يافته از لوسمى تأثير قابل توجهى برى افزايش يافت. نتايج يثوهش باشى عبدل آبادى، بيلهور و صارمى (هوس1) بيانگر اثربخشى توانبخشى شناختى بر كاركردهاى شناختى و حافظه افراد مبتلا به مالتيبل اسكلروز بود. همجنين يافتهاى يُّوهش زارع، شريفى و حاتمى (ITIF) نشان داد كه توانبخشى شناختى رايانهاى بر بهبود عملكرد حافظه آيندهنگ بيماران دهار آسيب مغزى اثر قابل توجهى داشت. يافتهاى يزٔوهش ارجمندنيا

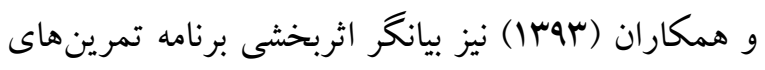
شناختى رايانهاى بر عملكرد حافظه فعال ديدارى فضايى

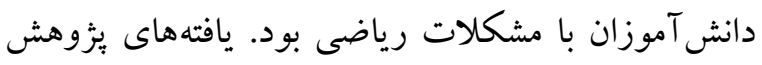

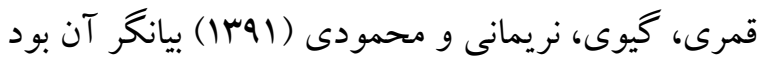
كه نرمافزار بيشبرد شناختى بر كاركردهاى اجرايى، بازدارى بِاسخ و حافظه فعال كود كان دجار نارساخوانى و كاستى توجه بيشفعالى تأثير قابل توجهى داشته است. 
و نوجوانان ه تا ها ساله طراحى كردهاند و ارجمندنيا آن را در سال 94سا ترجمه، انطباق و هنجاريابى كرده است (ارجمندنيا، وهسا). آزمون حافظه فعال يا حاف بكك كه در حدود يكك ساعت به صورت انفرادى اجرا مىشود داراى ه خردهآزمون يادآورى رقم، تطبيق ليست لغت، يادآورى ليست لغت، يادآورى ليست هجاهاى بىمعنى، يادآورى مكعب، حافظه مازها، يادآورى شنيدن، يادآورى شمارش و يادآورى رقم رو به عقب است. اين آزمون عملكرد مؤلفه حلقه واجشناختى را با مجموع نمرات يادآورى رقم، تطبيق ليست لغت، يادآورى ليست لغت و يادآورى ليست هجاهاى بىمعنى؛ عملكرد مؤلفه صفحه ديدارى فضايى را با مجموع نمرات يادآورى مكعب و حافظه مازها؛ و عملكرد مؤلفه مجرى مركزى را با مجموع نمرات يادآورى شنيدن، يادآورى شمارش و يادآورى رقم رو به عقب مورد سنجش قرار مىدهد. مجموع نمره عملكرد فرد در اين سه مؤلفه نيز بهره حافظه

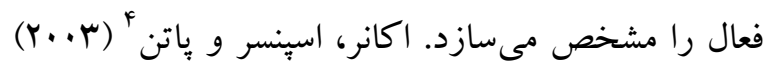

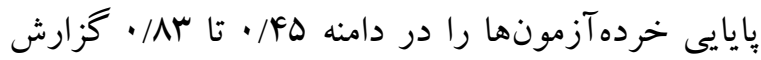

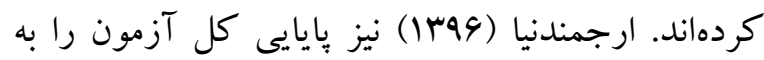

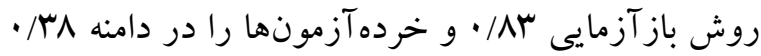

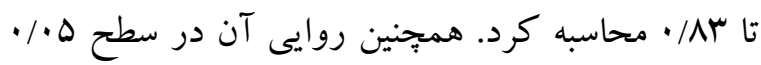
معنادار بود و روايى كل آن را V9/· به دست آورد. در يثوهش حاضر نيز ضريب يايايى و روايى كل بهترتيب

$$
\text { /VV }
$$

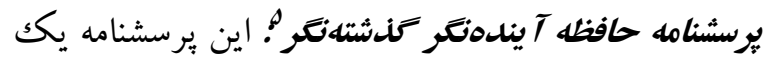
مقياس خودگزارشى است كه كرافورد، اسميت، مايلور، دلاسالا و لوجى در سال س...r ساخته است. يرسشنامه حافظه آيندهنگ گذشتهنگ 19 ماده دارد و در مقياس

\footnotetext{
${ }^{4}$. Oconnor, Spencer \& Patton

${ }^{5}$. prospective and retrospective memory questionnaire
}

اين يثوهش از نوع نيمه آزمايشى و طرح آن از نوع بيش آزمون و بِ آزمون با گروه كنترل است. جامعه آمارى يزوهش حاضر از كليه دانش آموزان كمشنواى بسر مدرسه استثنايى بسر انه سيناى Y شهرستان شهر كرد در سال تحصيلى IrqV تشكيل شده بود. براى انتخاب آزمودنى ها از روش نمونه كيرى در دسترس استفاده شد.

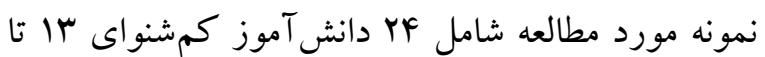
19 ساله بود. آزمودنىها به دو گروه بورد آنفرى تقسيم شدند. به دليل استفاده از روش يُزوهش شبهآزمايشى حجم مطلوب براى هر يك از خروهها · ا نفر است، البته در تعيين حجم نمونه به بيشينهاى بزّوهشى نيز توجه شده است. انتساب كروهها به آزمايش و كنترل نيز بهطور تصادفى صورت يذيرفت. ملاككهاى ورود به يُوهش دامنه سنى سا تا 19 سال، تحصيل در بِيههاى هفتم تا نهم، تمايل به شركت در يزوهش و زندگى با بدر و مادر بود. ملاككهاى خروج از مطالعه نيز غيبت بيشتر از دو جلسه در جلسات آموزشى، مصرف داروهاى محر كك يا غيرمحر كى، شركت همزمان در مداخله آموزشى مشابه، داشتن مشكلات بينايى، جسمى - حركتى يا اختلال هايى مانند كم توانى ذهنى و طلاق يا جدايى والدين بود.

ابزار

براى جمع آورى اطلاعات از ابزارهاى زير استفاده شد. مجموعه آزمون حافظه فعال براى كودكان': اين آزمون

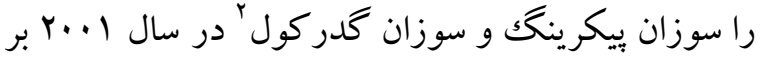
اساس مدل سه مؤلفهاى (حلقه واجشناختى، صفحه ديدارى فضايى و مجرى مركزى) بدلى و هيج به منظور سنجش حافظه فعال (شناخت و ويشرفت كلى بَ) كود كان

\footnotetext{
1. Working memory test battery for children (WMTB-C)

2. Pickering \& Gathercole

${ }^{3}$. Cognition \& general achievement
} 
يثزوهش حاضر براى مدير مدرسه و مادران دانش آموزان

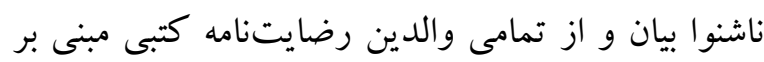
شركت فرزندشان در بزوهش اخذ شد. بعد از انتخاب

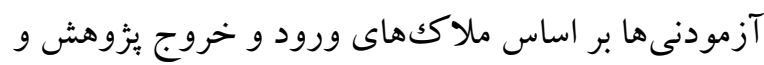
جايكزينى در گروه آزمايش و كنترل، مجموعه آزمون حافظه فعال براى كود كان و برسشنامه حافظه آيندهنگ كذشتهنگ براى هر دو گروه به عنوان بيش آزمون تكميل شل. كروه آزمايش بعد از اجراى بيش آزمون در برنامه توانبخشى شناختى مبتنى بر حافظه شركت كردند. اين برنامه بر اساس بروتكل توانبخشى شناختى مبتنى بر حافظه

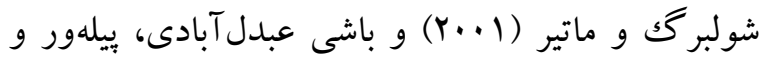

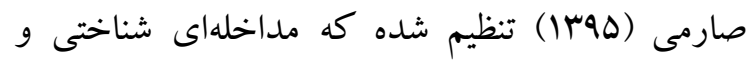
عصبشناختى است و بر توانايىهاى شناختى مبتنى بر حافظه تمركز دارد. در جلسات آموزش تمرينهايى داده مىشد كه مهارت هاى توجه، تمركز و حافظه را تقويت مى كردند. برنامه مداخلاتى در ·1 جلسه •ه دقيقهاى و هفتهاى دو جلسه براى گروه آزمايش اجرا شد. هدف و محتواى اين برنامه در جدول ا آمده است. از تمامى آزمودنىها، مجدداً مجموعه آزمون حافظه فعال براى درول

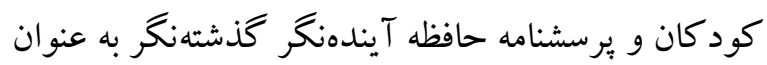
بس آزمون كرفته شد.
ليكرتى ينج درجهاى از هميشه كه بيانگر موافقت كامل

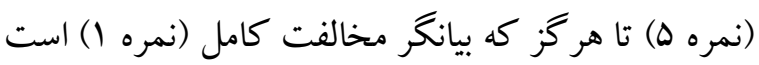
نمره گذارى مىشود. جمع نمرههاى به دست آمده در دامنه 19 تا •م قرار مى گيرد و نمره بيشتر به معنى

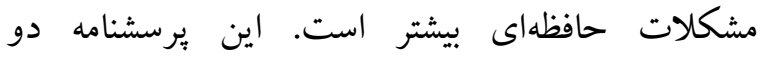
خردهمقياس حافظه آيندهنگ و حافظه گذشتهنگ دارد كه

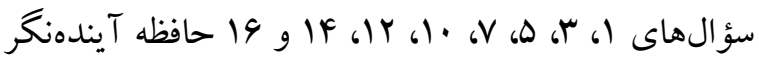

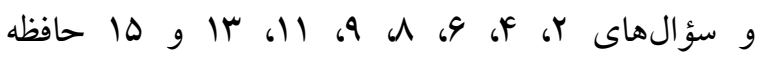
كذشتهنگ را ميىسنجد. در اين بيزوهش فقط از از خردهمقياس حافظه آيندهنگ استفاده شد. كرافورد و

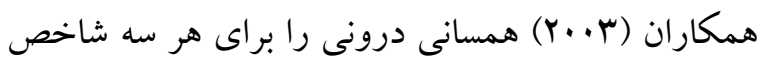
نمره كلى، حافظه آيندهنگ و حافظه گذشتهنگ به ترتيب

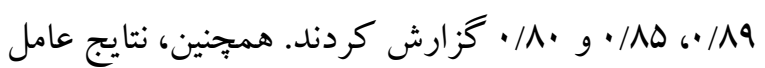
تائيدى نيز الكوى سه گانه بيشنهاد شده را تائيد مى كند. اين يرسشنامه در ايران توسط زارع، علىيور و مصطفايى (سوسו) هنجاريابى و مقدار آلفاى كرونباخ براى كل يرسشنامه سA/· به دست آمد. ضريب آلفاى كرونباخ

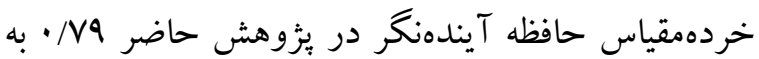
دست آمد. به منظور اجراى يزوهش، ابتدا جهت دريافت معرفىنامه

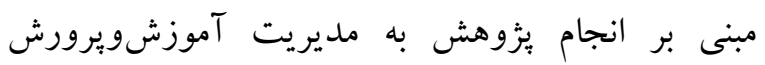

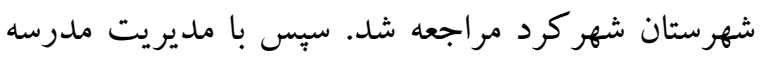

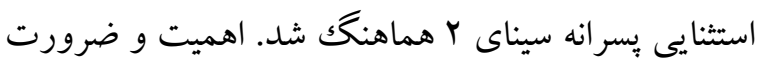

جدول اهدف و محتواى برنامه توانبخشى شناختى مبتنى بر حافظه

\begin{tabular}{|c|c|c|}
\hline محتوا & هدف & جلسه \\
\hline توضيح درباره ساختار جلسات، برنامهريزى، هدف گذارى، روشها و تمرينهاى شناختى & برقر ارى ارتباط و معرفى برنامه & 1 \\
\hline آموزش با كمكك ياديارها، تمرين حافظه ديدارى- تصويرى مانند بازى يادآورى جهره & تقويت حافظه ديدارى - تصويرى & $r$ \\
\hline 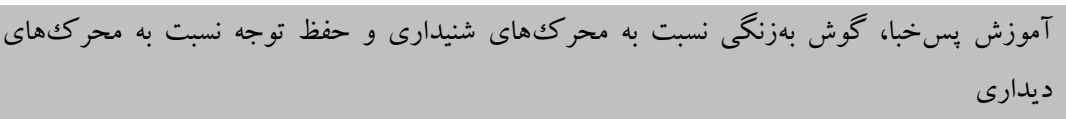 & تقويت حافظه شنيدارى- ديدارى & $r$ \\
\hline ارائه بازىهاى مربوط به سرعت يردازش اطلاعات و هماهنگى ديدارى - فضايى مانند بازى صورتككهاى & تقويت حافظه ديدارى - فضايى & p \\
\hline
\end{tabular}




\begin{tabular}{|c|c|c|}
\hline كفتن اعداد طبق الخو، الكويابى مستقيم و معكوس، تكميل كردن جدولهاى كلمات، تداعىهاى زوجى & $\begin{array}{c}\text { تقويت حافظه عددى و تداعى } \\
\text { كلمات }\end{array}$ & $\Delta$ \\
\hline تغيير توجه در حافظه رويدادى، توجه انتخابى و يردازش توجه، سازماندهى كلامى، گسترش معنايى & تقويت حافظه رويدادى و بسط & 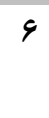 \\
\hline ياديارها، تصويرسازى زمانى و مكانى با يادآورى تجربههاى كذشته اخير و فورى & تقويت حافظه زمانى و مكانى & $\checkmark$ \\
\hline اجر اي دستور العمل هاى حر كتى يككمرحلهاى و جندمرحلهاى مانند طبقهبندى و تمايز گذارى & تقويت حافظه حر كتى & $\Lambda$ \\
\hline تصويرسازى و حل مساله بهصورت ذهنى، برنامهريزى، حذف تدريجى نشانههاى حافظهاى & تقويت فراحافظه & 9 \\
\hline مرورى بر محتواى جلسات و آماده كردن آزمودنى براى خروج از برنامه توانبخشى شناختى مبتنى بر & 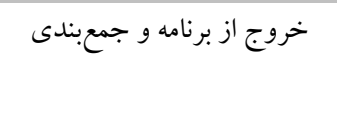 & $1 \cdot$ \\
\hline
\end{tabular}

يافتهاى توصيفى نشان داد كه سن آزمودنىها در گروه آزمايش با ميانگين و انحراف استاندارد در گروه كنترل با ميانگين و انحراف استاندارد IF/Or و 19V • بود. ميانكين، انحر اف معيار و نرماليتى متغيرهاى و نيمرخ حافظه فعال (مجرى مركزى، صفحه ديدارى فضايى، حلقه واجشناختى) و حافظه آيندهنگ در دو كروه آزمايش و كنترل در موقعيت يش آزمون و

$$
\text { بس آزمون در جدول r آمده است. }
$$

در ئزوهش حاضر براى تجزيهوتحليل دادههاى به دست آمده از روش هاى آمار توصيفى مانند شاخص هاى ميانكين و انحراف استاندارد و از آمار استنباطى، از آزمون آمارى تحليل كوواريانس جندمتغيرى استفاده شد. تحليل دادهها با استفاده از نسخه FF نرمافزار آمارى SPSS

نافتها

جدول r شاخصهاى توصيفى نيمرخ حافظه فعال و حافظه آيندهنكر در كروه آزمايش و كنترل

\begin{tabular}{|c|c|c|c|c|c|c|c|}
\hline \multicolumn{3}{|c|}{ تروه كنترل } & \multicolumn{3}{|c|}{ كروه آزمايش } & \multirow[t]{2}{*}{ موقعيت } & \multirow[t]{2}{*}{ متغيرها } \\
\hline 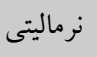 & انحر اف معيار & ميانگين & 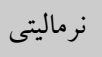 & انحر افمعيار & ميانكين & & \\
\hline ./Ir & $1 / 1 \Lambda$ & $91 / 94$ & سr/. & $1 / 19$ & $91 / v 0$ & بيش آزمون & مجرى مر كزى \\
\hline$\cdot / A V$ & $1 / 4$ & $91 / 14$ &.$/ 1 \wedge$ & $1 / K F$ & $99 / 10$ & 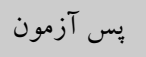 & \\
\hline .194 & $1 / r r$ & $\Delta r / \Delta I$ & .119 & $1 / 91$ & $\Delta F / F G$ & ي بيش آزمون & صفحه ديدارى فضايى \\
\hline$\cdot / 11$ & $1 / \pi$. & $\Delta F / \Delta \Delta$ & I/KI & $1 / \cdot 1$ & $G Y / \Delta V$ & 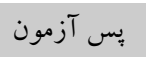 & \\
\hline$\cdot / \Delta r$ & $1 / \Delta 9$ & $V F / A V$ & .1 .9 & $1 / 91$ & $V \Delta / Y V$ & 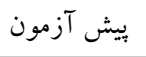 & حلقه واجشناختى \\
\hline$\cdot / V^{F}$ & $1 / 4 \lambda$ & $V \Delta / \cdot r$ & . $/ F r$ & $1 / \Delta F$ & $11 / 4 \mu$ & 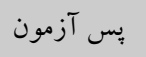 & \\
\hline.$/ 19$ & $\cdot / M$ & $F \mid / 1$. &.$/ 11$ &.$/ 91$ & $F \mid / \cdot V$ & بيش آزمون & \multirow[t]{2}{*}{ حافظه آيندهنكر } \\
\hline$\cdot / r$ & $\cdot / \Lambda \Delta$ & $F \cdot / \cdot V$ & .1 .9 & - /AF & $r V / l Q$ & پِس آزمون & \\
\hline
\end{tabular}

وجود يكك متغير مستقل (برنامه تو انبخشى شناختى مبتنى بر حافظه) و سه متغير وابسته مجرى مركزى، صفحه ديدارى فضايى، حلقه واجشناختى از يكك آزمون آمارى
شاخصهاى توصيفى نمرات بيش آزمون و يس آزمون متغيرهاى ئزوهش دو گروه آزمايش و كنترل در جدول r ارائه شده است. براى تعديل اثر بيش آزمون و به علت 
بنابراين مفروضههاى آزمون آمارى تحليل كوواريانس جندمتغيرى برقرار است. به اين منظور، متغيرهاى مجرى مركزى، صفحه ديدارى فضايى، حلقه واجشناختى در گروه آزمايش و كنترل در ييشفرض

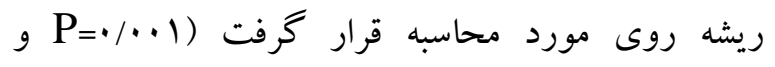
(F=119/49)؛ بنابر اين گروه آزمايش و كنترل حداقل درد يكى از متغيرها تفاوت معنادارى دارند. به منظور بیىبردن به اين تفاوت، از آزمون آمارى تحليل كوواريانس جندمتغيرى (مانكووا) استفاده شد كه نتايج هر يكك در آرول جدول بآمده است.
تحليل كوواريانس جندمتغيرى (مانكووا) و همجنين يك متغير وابسته حافظه آيندهنگ از يكك آزمون آمارى تحليل كوواريانس تككمتغيرى (آنكووا) ديخر استفاده شد. براى تعيين اثربخشى برنامه مداخلاتى بر نيمرخ حافظه

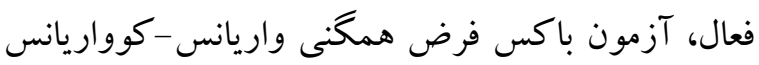

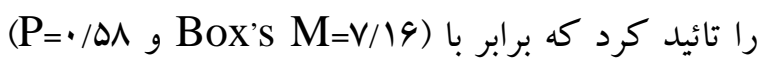

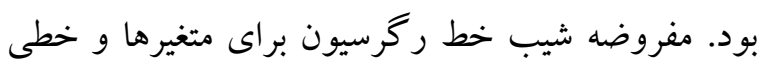
بودن رابطه متغيرها برقرار بود. آزمون كرويت بارتلت حاكى از وجود همبستخى كافى بين متغيرهاى وابسته بود (P=•••l)

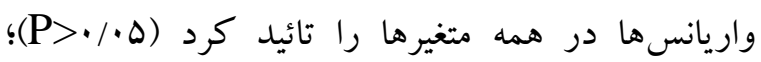

جدول r نتايج تفكيكى مانكووا براى مجرى مركزى، صفحه ديدارى فضايى، حلقه واجشناختى

\begin{tabular}{|c|c|c|c|c|c|c|c|}
\hline مجذور اتا & معنادارى سطح & نسبت F & مجذوروات & درجا آدى & مجذورات & متغير هاى وابسته & منابع تغيير \\
\hline r & $\cdot \cdots \cdot 1$ & $11 / 19$ & $9 / 94$ & 1 & $9 / 94$ & بيش آزمون & مجرى مركزى \\
\hline \multirow[t]{3}{*}{.191} & $\cdot / \cdots 1$ & $M T / F D$ & $r V / q I$ & 1 & $r V / q)$ & كروه & \\
\hline & & & $\cdot / 19$ & 19 & $19 / 4 \Lambda$ & خطا & \\
\hline & & & & rr & $\Delta V / \wedge q$ & كل & \\
\hline$\cdot|r|$ & $\cdot / r$ & $9 / 91$ & $V / I V$ & 1 & $V / I V$ & بيش آزمون & صفحه ديدارى \\
\hline \multirow[t]{3}{*}{$\cdot 194$} & $\cdot / \cdots, 1$ & וT/r & $r r / q 1$ & 1 & $r r / q 1$ & كروه & فضايى \\
\hline & & & $\cdot / V F$ & 19 & $|F / Y|$ & خطا & \multirow{6}{*}{ حلقه واجشناختى } \\
\hline & & & & r & $4 N / 19$ & كل & \\
\hline.$/ 1 F$ & 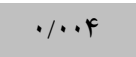 & $F / 91$ & r/I & 1 & & بيش آزمون & \\
\hline \multirow[t]{3}{*}{$\cdot 109$} & $\cdot / \cdots, 1$ & r/ו & Tr/TV & 1 & Tr/TV & كروه & \\
\hline & & & $1 / \cdot r$ & 19 & $19 / 94$ & خطا & \\
\hline & & & & r & $\Delta 9 / 91$ & كل & \\
\hline
\end{tabular}

مجرى مركزى، صفحه ديدارى فضايى و حلقه واجناختى به علت اثر مداخله است.

براى تعيين اثربخشى برنامه مداخلاتى بر آنس عافظه

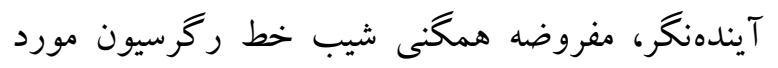

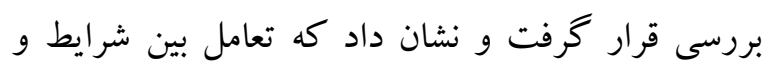

با توجه به نتايج جدول س، گروه اثر معنادارى بر نمرات

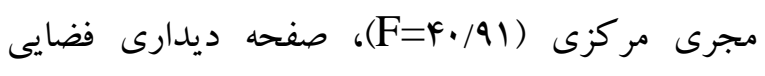
(F=FI/Vq)

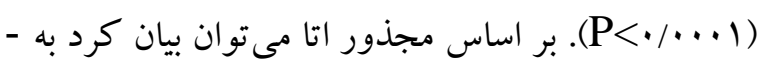
ترتيب 91، بو و 99ه درصد تغييرات هر يكك از متغيرهاى 


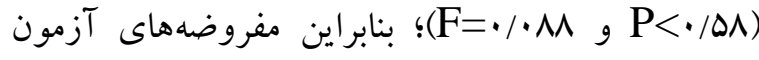
آمارى تحليل كوواريانس تككمتغيرى برقرار است كه نتايج آن در جدول \& گزارش شده است.

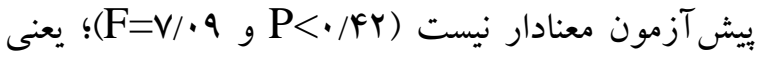
دادهها از همكنى شيب رگر سيون حمايت مى كند. نتايج

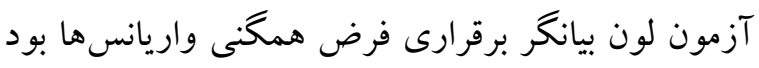

جدول † نتايج تحليل كوواريانس تكتمتغيرى حافظه آيندهنكر

\begin{tabular}{|c|c|c|c|c|c|c|c|}
\hline توان & مجذور اتا & معنادارى سطح & نسبت F & مجذانكين & آزادى درجه & مجذوروات مجموع & منابع تغيير \\
\hline . & $\cdot / 4 \Lambda$ &.$/ . .1$ & $\Delta / \cdot V$ & $r r q / l^{f}$ & 1 & $r r q / / F$ & بيش آزمون \\
\hline \multirow[t]{3}{*}{.$/ 9 Y$} &.$/ 01$ & $\cdot / \cdots \cdot 1$ & $9 / .1$ & Fro/rA & 1 & $F Y \Delta / r \Lambda$ & تروه \\
\hline & & & & $F V / 19$ & 19 & ৯৭९/.Y & خطا \\
\hline & & & & & r & $|A K| / T V$ & كل \\
\hline
\end{tabular}

ناشنوا و كانلويولوس و همكاران (19) مبنى بر تأثير مثبت و معنادار توانبخشى شناختى بر حافظه فعال نوجوانان بقا يافته از لوسمى همسو بود. با نتايج يزوهش كولستاد و

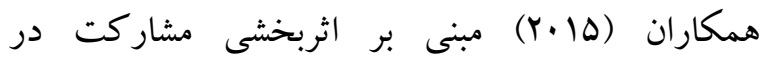
فعاليتهاى شناختى اوقات فراغت بر بهبود حافظه افراد

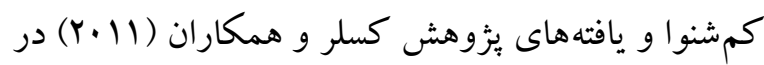
خصوص اثربخشى برنامه بازتوانى شناختى آنلاين بر

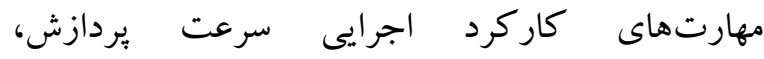
انعطاف يذيرى شناختى و حافظه اخبارى كلامى و بينايى كود كان با آسيب مغزى همخوانى دارد. علاوه بر اين با لـا

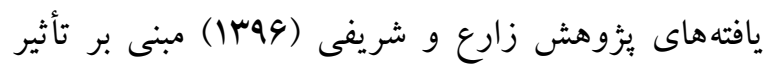
مثبت و معنادار توانبخشى شناختى رايانهاى بر بهبود

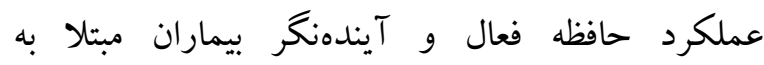

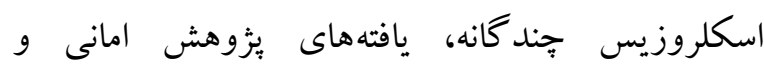
همكاران (1M94) در خصوص تأثير جشمخير توانبخشى شناختى بر كار كردهاى اجرايى حافظه فعال نوجوانان بقا

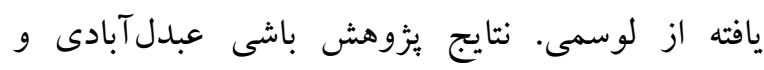

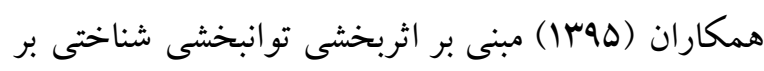

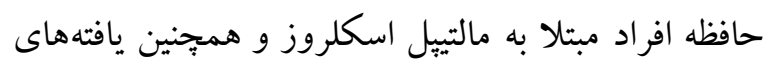

در اين تحليل، متغير بيش آزمون بهدليل همبستگى با يس آزمون تعديل شده است. با توجه به نتايج جدول F)

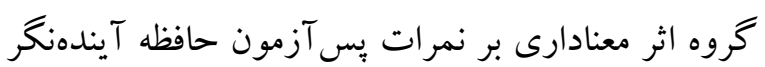

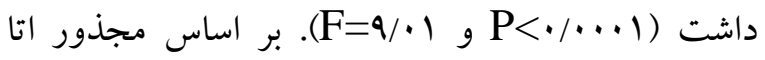
مىتوان عنوان كرد كه اله درصد تغيير متغير حافظه آيندهنگر به علت اثر مداخله است.

اين يثزوهش با هدف بررسى اثربخشى برنامه توانبخشى شناختى مبتى بر حافظه بر نيمرخ حافظه فعال و حافظه آيندهنكر دانش آموزان كمشنوا انجام شد. نخستين يافته يثزوهش حاضر بيانكر تأثير قابل توجه برنامه توانبخشى شناختى مبتنى بر حافظه بر حافظه فعال دانش آموزان كمشنوا بود. اين يافته با نتايج يزوهش يرز مارتين و

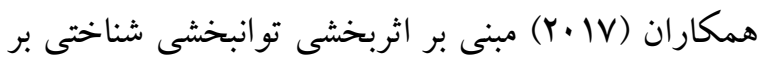

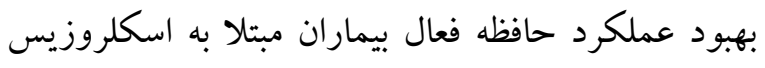
جند كانه، نتايج ئزوهش كاستلينو و همكاران (19 (Y) در خصوص اثربخشى قابلتوجه آموزش و توانبخشى شنيدارى بر عملكرد شناختى و حافظه افراد بزرگكسال 
تو انبخشى به حوزه شناخت و حافظه، به ويزه حافظه فعال توجه ويزهاى دارد و محتواى جلسات آن بر همين اساس بـ به تدوين شده است؛ بنابراين، دور از انتظار نيست كه اجراى جنين برنامهاى سبب بهبود حافظه فعال دانش آموزان كم شنوا شود.

دومين يافته بثزوهش حاضر بيانگر تأثير قابل توجه برنامه توانبخشى شناختى مبتنى بر حافظه بر حافظه آيندهنگ

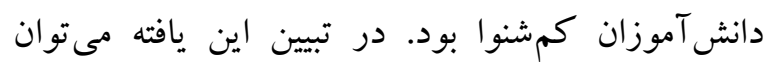
كفت كود كان و نوجوانان كمشنوا در حافظه كه حافظه آيندهنگر هم بخشى از آن است با جالشهاى عمدهاى

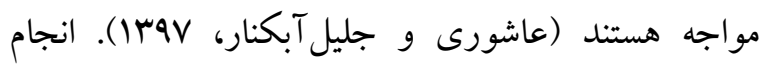
تكاليف حافظه آيندهنگ مستلزم اين است كه افراد اعمال هدفمندى را در حالى كه دركير در فعاليتهاى جارى ديخرى هستند به ياد آورند (مير و رىمرمت، YV) بحث هاى رايجى در ارتباط با حافظه آيندهنگ وجود دارد و از اين عقيده كه تكاليف حافظه آيندهنگ به بهور خودبهخود با قصدها و نيتها ارتباط دارند حمايت مى كنند. تكاليف حافظه آيندهنك, به عنوان بخش مهمى لئ از عملكردهاى روزمره هستند كه زيستن را امكانيذير مىسازد. به بيان ديخر، اگر حافظه آيندهنگر به نحو

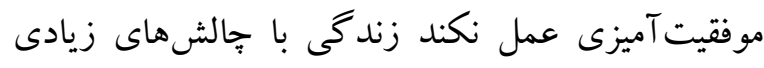
مواجه مىشود (فيش، ويلسون و منلى، · ·. (Y). به نظر مىرسد توانبخشى شناختى مبتنى بر حافظه بتواند به

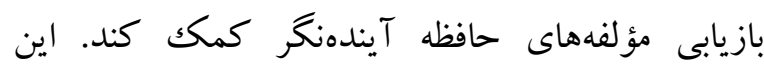
رويكرد اين ايده را مطرح مى كند كه اختلالهاى حافظه

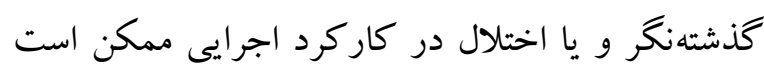
در زير آسيبهاى حافظه آيندهنگ رينهان باشد (ميونى و

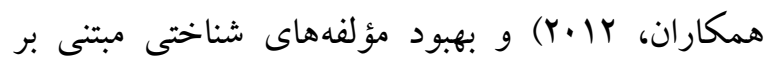

يثزوهش زارع و همكاران (IMAF) در خصوص تأثير قابل توجه توانبخشى شناختى رايانهاى بر بهبود عملكرد حافظه آيندهنگ بيمار ان دجار آسيب مغزى همخوانى داشت. در تبيين اين يافته كه برنامه توانبخشى شناختى مبتنى بر

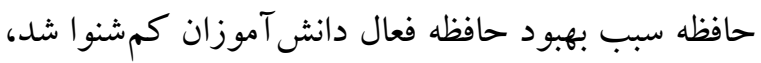
مىتوان كفت دانش آموزان كمشنوا در حافظه، به ويزه حافظه فعال مشكلات قابل توجهى دارند (كركك و همكاران، ها +Y). از طرفى، امروزه حافظه فعال به عنوان يكى از حوزههاى مهم مورد توجه قرار كرفته است (T) (T) و يكى از شاخص هاى هوش يا به عبارتى اصلىترين بستر هوش در نظر كرفته مىشود (اسبجورن، نورمن،

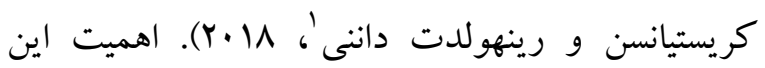
مسئله در كود كان كمشنوا دو جندان است. جرا كه حافظه كودكان عادى با انجام فعاليتهاى روزمره بهطور خودبخود افزايش مىيابد ولى دانش آموزان كمشنوا كمتر در فعاليتهاى روزمره شركت مى كنند و توان ذهنى آنها به جالش كشيده نمىشود يا انتظاراتى اندكى

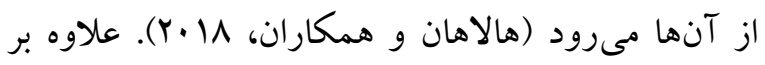
اين، دانشآموزان كمشنوا به دليل وجود آسيبهاى جدى در فرايندهاى شناختى به ويثه در حافظه با

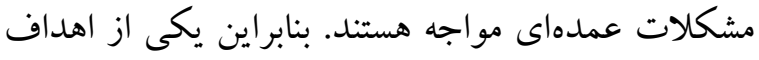
اصلى آموزش اين كود كان، توجه به مشكلات شناختى

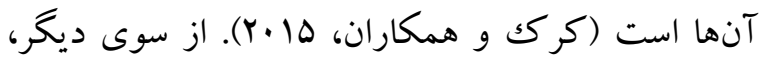
توانبخشى شناختى مبتنى بر حافظه به فرايندهاى شناختى به منظور يادآورى رويدادهايى كه در حال حاضر اتفاق مىافتد و در راستاى آن عملى در آينده انجام خواهد شد توجه دارد (بويت و رامل، Y Y.Y). در واقع اين برنامه

${ }^{1}$. Esbjørn, Normann, Christiansen \& Reinholdt-Dunne 
تعميم نتايج احتياط كرد؛ بنابر اين بيشنهاد مىشود كه در يثزوهشهاى بعدى به سن و جنسيت آزمودنىها و ويز گیىهاى شخصيتى آنها توجه شود، سواد والدين و وضعيت اجتماعى و اقتصادى آنها مدنظر قرار كيرد و در يخوهشهاى آتى به نوع آسيب شنوايى و وسيله كمكك شنوايى توجه گردد، ئزوهش هاى بعدى با حجم نمونه بيشترى انجام شود و آزمون بِيخيرى به عمل آيد. همجنين ييشنهاد مىشود كه از برنامه توانبخشى شناختى مبتنى بر حافظه براى ساير گرووهاى دانش آموزان با نيازهاى ويزٔه

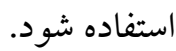

\section{نتيجه كيرى}

بهطور كلى، دانش آموزان كمشنوا نمىتواند بهور خودبهخودى و بدون آموزشهاى ويزه از ظرفيت بالقوه حافظه خود به نحو مطلوبى استفاده كنند. آنها در صورت برخوردارى از برنامه توانبخشى شناختى مناسب خواهند توانست همانند همسالان عادى خود از ظرفيت حافظه شان به نحو مناسبى بهرهمند شوند (انگل)، 11 ·Y)؛ جرا كه آموزش از طريق توانبخشى شناختى مبتنى بر حافظه موجب بهبود حافظه فعال و حافظه آيندهنگ

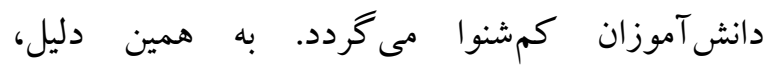
فراهمسازى امكانات قابل دسترسى به منظور استفاده از برنامه توانبخشى شناختى مبتنى بر حافظه براى افراد

$$
\text { كمشنو اضرورت دارد. }
$$

\section{سياسگز ارى}

اين بثزوهش بر گرفته از باياننامه كارشناسى ارشد دانشگاه آزاد اسلامى واحد نجف آباد با كد بr. IFFG است كه مجوز آن از آموزش و برورش استثنايى شهرستان

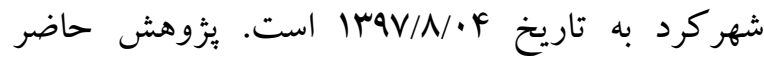

حافظه باعث بهبود حافظه آيندهنگ شود (فيش و

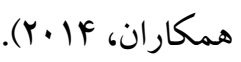
از طرف ديخر، برنامه توانبخشى شناختى مبتى بر

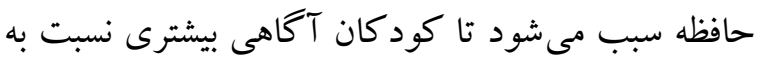
حافظه و توانايىهاى شناختى خود ويدا كنند و راههاى مناسبترى براى رفع مشكلات مرتبط با حافظه آيندهنگر

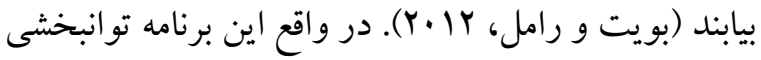
به حوزه شناخت، حافظه و توجه اهميت مىدهد و محتواى جلسات آن بر همين اساس تدوين شده است. به همين دليل برنامه توانبخشى شناختى مبتنى بر حافظه كه

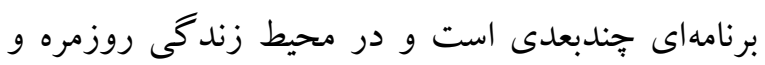

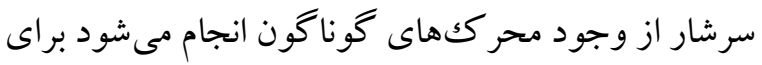
بهبود حافظه آيندهنگ كودكان كمشنوا بسيار ضرورى است. علاوه بر اين، از آن جايى كه برنامه توانبخشى مذكور شامل فعاليتهاى جذاب و مورد علاقه كود كان است و اين فعاليتها از طريق بازى ارائه مىشوند

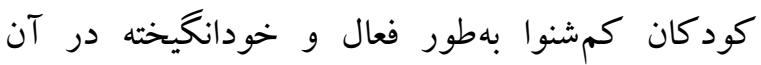
مشاركت مى كنند و به نظر مىرسد تأثير قابل توجهى بر تقويت حافظه آيندهنگ آنها داشته باشد. يس دور از انتظار نيست كه آموزش برنامه توانبخشى شناختى مبتنى بر

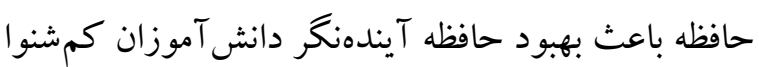

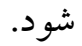

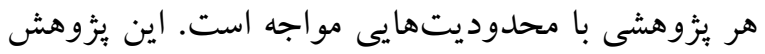
نيز از جنين قاعدهاى بيروى مى كند. يُزوهش حاضر فقط بر روى دانش آموزان كمشنواى يسر سا تا 19 ساله انجام

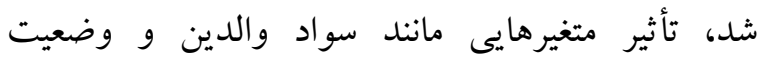
اجتماعى و اقتصادى آنها مورد بررسى قرار نكرفت، حجم نمونه كم بود و با توجه به محدوديت زمانى، فرصتى براى اجراى آزمون بيخيخ فرى اهم نشد كه بايد در 
Boywitt CD, Rummel J. (2012). A diffusion model analysis of task interference effects in prospective memory. Mem Cogn, 40, 70-82.

Castiglione A, Benatti A, Velardita C, Favaro D, Padoan E, Severi D, Pagliaro M, Bovo R, Vallesi A, Gabelli C, Martini A. (2016). Aging, cognitive decline and hearing loss: Effects of auditory rehabilitation and training with hearing aids and cochlear implants on cognitive function and depression among older adults. Audiology \& NeuroOtology, 21(1), 21-28.

Crawford, JR, Smith G, Maylor EA, Della Sala S, Logie RH. (2003). The prospective and retrospective memory questionnaire (PRMQ): Normative data and latent structure in a large non-clinical sample. Memory (Hove, England), 11(3), 261-275.

Dagenais E, Rouleau I, Tremblay A, Demers M, Roger É, Jobin C, Duquette P. (2016). Role of executive functions in prospective memory in multiple sclerosis: Impact of the strength of coaction association. Journal of Clinical and Experimental Neuropsychology, 38(1), 127140.

Engle RW. (2018). Working memory and executive attention: A revisit. Perspectives on Psychological Science, 13(2) 190-193.

Esbjøm BH, Normann N, Christiansen BM, ReinholdtDunne ML. (2018). The efficacy of group metacognitive therapy for children (MCT-c) with generalized anxiety disorder. An open trial. Joumal of Anxiety Disorders, 53, 16-21.

Ferguson M, Henshaw H. (2015). Auditory training can improve working memory, attention, and communication in adverse conditions for adults with hearing loss. Frontiers in Psychology, 6, 1-7.

Fish JE, Manly T, Kopelman MD, Moris RG. (2014). Emorless leaming of prospective memory

$$
\begin{aligned}
& \text { حامى مالى نداشته است. از دانش آموزان كمشنوا كه در } \\
& \text { اين يزٔوهش مشاركت داشتند قدردانى مىشود. هم:جنين } \\
& \text { از مادران اين دانشآموزان و مديريت محترم مدرسه } \\
& \text { استثنايى بِرانه سيناى Y شهرستان شهر كرد كه در انجام } \\
& \text { اين وُزوهش مساعدت و همراهى كردند سياسگزارى } \\
& \text { مى كردد. }
\end{aligned}
$$

\section{References}

Alloway TP, Bibile V, Lau G. (2013). Computerized working memory training: Can it lead to gains in cognitive skills in students? Computers in Human Behavior, 29 (3), 632-638.

Amani O, Mazaheri MA, Nejati V, Shasian B. (2017). Effect of cognitive rehabilitation on executive functions in adolescent survivors of leukemia: A randomized and controlled clinical trial. Archives of Rehabilitation, 18(1), 73-82. (In Persian).

Arjmandnia AA, Sharifi A, Rostami R. (2014). The effectiveness of computerized cognitive training on the performance of visual-spatial working memory of students with mathematical problems. Journal of Leaming Disabilities, 3(4), 6-24. (InPersian).

Ashori M. (2019). Effect of cognitive rehabilitation program based on memory on executive functions and cognitive emotion regulation in children with hearing impairment. Psychology of Exceptional Individuals, 9(34), 197-217. (In Persian).

Bashi Abdolabadi H, Pilevar S, Saram AA. (2016). The effect of cognitive rehabilitation on cognitive function, memory, depression, and anxiety in patients with multiple sclerosis. The Neuroscience Joumal of Shefaye Khatam, 4(3), 28-40. (In Persian). 
tasks: An experimental investigation in people with memory disorders. Neuropsychological Rehabilitation, 25(2), 1-30.

Ghamari Givi H, Narimani M, Mahmoodi H. (2012). The effectiveness of cognition-promoting software on executive functions, response inhibition and working memory of children with dyslexia and attention deficit/ hyperactivity. Journal of Leaming Disabilities, 3(2), 98-115. (In Persian).

Hallahan DP, Kauffman JM, Pullen PC. (2018). Exceptional leamers: an introduction to special education (14th Ed). Published by Pearson Education, Inc.

Hamilton H. (2011). Memory skills of deaf leamers: Implications and applications. American Annals of the Deaf, 156(4), 402-423.

Kanellopoulos A, Andersson S, Zeller B, Tamnes CK, Fjell AM, Walhovd KB, Westlye LT, Fosså SD, Ruud E. (2016). Neurocognitive outcome in very long term survivors of childhood acute lymphoblastic leukemia after treatment with chemotherapy only. Pediatric Blood \& Cancer, 63(1), 133-138.

Kesler SR, Lacayo NJ, Jo BA. (2011). Pilot study of an online cognitive rehabilitation program for executive function skills in children with cancer-related brain injury. Brain Inj, 25(1), 101-112.

Kirk S, Gallagher G, Coleman MR. (2015). Educating Exceptional Children (14th Ed). Cengage Learning, Printed in the United States of America

Kollstad AM, Anne-Stine Dolva AS, Kleiven J. (2015). Independent and supported physical leisure activities of adolescents with Down syndrome. Ergoterapeuten.

Landsberger SA, Diaz DR. (2010). Inpatient psychiatric treatment of deaf adults: demographic and diagnostic comparisons with hearing inpatients. Psychiatry Serve, 61, 196-99.

Lawrence BJ, Jayakody D, Henshaw H, Ferguson MA, Eikelboom RH, Loftus AM, Friedland PL. (2018). Auditory and cognitive training for cognition in adults with hearing loss: A systematic review and meta-analysis. Trends in hearing, 22, 1-13.

Lawyer G. (2018). Deaf education and deaf culture: Lessons from Latin America. American Annals of the Deaf, 162(5), 486-8.

Meier B, Rey-Mermet A. (2017). After-effects without monitoring costs: The impact of prospective memory instructions on task switching performance. ActaPsychologica, 1-15.

Mioni G, Stablum F, McClintock SM, Cantagallo A. (2012). Time-based prospective memory in severe traumatic brain injury patients: The involvement of executive functions and time perception. Joumal of the International Neuropsychological Society, 18(4), 697-705.

Oconnor B, Spencer FH, Patton W. (2003). The role of working memory in relation to cognitive functioning in children. Aust J Psychol, 55, 213.

Pérez-Martín MY, González-Platas M, Eguíadel RioP, Croissier-Elías C, Jiménez Sosa A. (2017). Efficacy of a short cognitive training program in patients with multiple sclerosis. Neuropsychiatric Disease and Treatment, 13, 245-252.

Roy RA. (2018). Auditory working memory: A comparison study in adults with normal hearing and mild to moderate hearing loss. Global Joumal of Otolaryngology, 13(3), 1-14.

Shin HY, Hwang HJ. (2017). Mental health of the people with hearing impairment in Korea: A population-based cross-sectional study. Korean Journal of Family Medicine, 38(2), 57-63. 
Sholberg MM, Mateer CA. (2001). Cognitive rehabilitation: An integrative neuropsychological approach. New York: The Guilford press.

Taljaard DS, Olaithe M, Brennan-Jones CG, Eikelboom RH, Bucks R. (2016). The relationship between hearing impairment and cognitive function: A meta-analysis in adults. Clinical Otolaryngology, 41, 718-729.

Zare H, Alipur A, Mostafaie A. (2014). Standardization and validity retrospective memoryprospective. Social Cognition, 3(1), 45-56. (In Persian).

Zare H, Sharifi A. (2017). The effect of computerized cognitive rehabilitation on working \& prospective memory function in Multiple Sclerosis patients. Joumal of Cognitive Psychology, 5(1), 1-10. (In Persian).

Zare H, Sharifi AA., Hatami J. (2015). The impact of computerized cognitive rehabilitation on prospective memory in patients with traumatic brain injury. Joumal of Applied Psychology, 1(33), 63-77.(In Persian). 